\title{
Implementation of Harmonised European Transition Altitude (HETA)
}

\author{
The area with harmonized transition altitude in Europe is expanding slowly but surely
}

\author{
Jiř́ Frei \\ Department of Air Transport, \\ Faculty of Transportation Sciences, Czech Technical University \\ Horská 3, Praha 2, 128 03, Czech Republic \\ frei@ans.cz
}

\begin{abstract}
Since 2010 there has been a noticeable effort to implement harmonized European transition altitude (HETA). This effort resulted in establishing of several working groups. As outputs were proposed three options but no mandatory implementation rules for European countries (resp. air navigation services providers). Nowadays each country evaluates impacts of implementation of one of three proposed solutions and some countries even implement kind of harmonized transition altitude in cooperation with neighboring countries (Slovakia, Hungary and Austria). This article briefly describes the general problem in section I and II. Impacts of all three proposed options by working group on involved subjects such as crew, controllers, but also environment or safety are evaluated. The end of the article describes in details the way of implementation in Slovakia and some case studies related to altimeter setting rules in the area of common interest at the interface between FIR Prague, Bratislava and Vienna.
\end{abstract}

Keywords-transition altitude, transition level, transition layer, HETA - Harmonised European Transition Altitude, aerodrome QNH, regiona l QNH,

\section{TERMINILOGY AND DEFINITION}

Transition altitude (TA) - the altitude at or below which the vertical position of an aircraft is controlled by reference to altitudes.

Transition level (TL) - the lowest flight level available for use above the transition altitude.

Transition layer - The airspace between the transition altitude and the transition level.

(source: ICAO Doc. 8168, ICAO Doc. 4444)

\section{BACKGROUND}

Efforts to harmonize the TA in Europe (on the ground EUROCONTROL) origins date back to year 2000. EU member states (Single Sky Committee - SSC/41 6. -7.4.2011) approved establishing of common working group consisting of EC, EASA and EUROCONTROL members. Working group was called "Harmonized European Transition Altitude Task Force" - HETA-TF. HETA-TF should participate in the processing of potential solutions evaluation and preparation of underlays for regulatory harmonization of "European TA". The activities related to HETA-TF were finished in the end 2011 by elaboration of preliminary evaluation of impact of the implementation HETA.

Among factors leading to the idea of harmonization belongs:

\section{A. Various range of TA values}

There is really wide range of values of transition altitudes across Europe. Each country has at least one value of TA in its airspace. Many countries have two or even more values of TA (e.g. Italy - values from 3 to 10 thousand feet AMSL) depending on many factors. Furthermore, values of TA can changed during the day in some countries (The UK / NATS). See table I and figure 2 and 3 for detailed scheme of TA values in Europe.

TABLE I. TA VALUES IN EUROPE

\begin{tabular}{|c|c|c|}
\hline Country & ANSP & TA value(s) [ft] \\
\hline $\mathbf{U K}$ & NATS & $\begin{array}{c}3000 / 4000 / \\
5000 / 6000\end{array}$ \\
\hline France & DSNA & $\begin{array}{c}3000 / 4000 / \\
5000 / 6200 / 7000 \\
\end{array}$ \\
\hline Belgium & Belgocontrol & 4500 \\
\hline Netherlands & LVNL & 3000 \\
\hline Denmark & Naviair & $3000 / 5000$ \\
\hline Germany & DFS & 5000 \\
\hline Switzerland & Skyguide & $\begin{array}{l}5000 / 6000 / \\
7000 / 17000\end{array}$ \\
\hline Italy & ENAV & $\begin{array}{c}3000 / 4000 / \\
5000 / 6000 / \\
7000 / 8000 / \\
10000\end{array}$ \\
\hline Sweden & $\mathrm{LFV}$ & $\begin{array}{c}5000 / 6000 / \\
9000\end{array}$ \\
\hline Poland & PANSA & 6500 \\
\hline Czech Republic & ANS CZ & 5000 \\
\hline Slovakia & LPS & $8000 / 10000$ \\
\hline Austria & Ausotrocnotrl & $\begin{array}{l}4000 / 5000 / \\
7000 / 11000\end{array}$ \\
\hline Slovenia & Slovenia control & 10500 \\
\hline Croatia & $\mathrm{CCL}$ & 9500 \\
\hline Bosnia & BHANSA & 9500 \\
\hline Montenegro & SMATSA & 10000 \\
\hline
\end{tabular}




\begin{tabular}{|c|c|c|}
\hline Albania & ANTA & $\mathbf{1 0 0 0 0}$ \\
\hline Macedonia & M-NAV & $\mathbf{1 1 0 0 0}$ \\
\hline Bulgaria & BULATSA & $\begin{array}{c}\mathbf{5 0 0 0} / \mathbf{1 1 0 0 0} / \\
\mathbf{1 2 0 0 0}\end{array}$ \\
\hline Romania & ROMATSA & $\begin{array}{c}\mathbf{3 0 0 0} / \mathbf{4 0 0 0} / \\
\mathbf{5 0 0 0} / \mathbf{9 0 0 0}\end{array}$ \\
\hline Moldavia & MoldATSA & $\mathbf{4 0 0 0}$ \\
\hline
\end{tabular}

Note: TA values valid until 12/2015, (source: national AIPs)

\section{$B$. The necessity to change altimeter settings}

It is obvious that the landing and approach phase of the flight are considered as the most dangerous. Current settings of TA values in Europe causes the necessity to change the altimetry settings (from value of $\mathrm{QNE}=1013,25 \mathrm{hPa}$ to value of aerodrome QNH) during the critical phase of flight. (For detailed information about workload on flight deck see section VIII Workload).

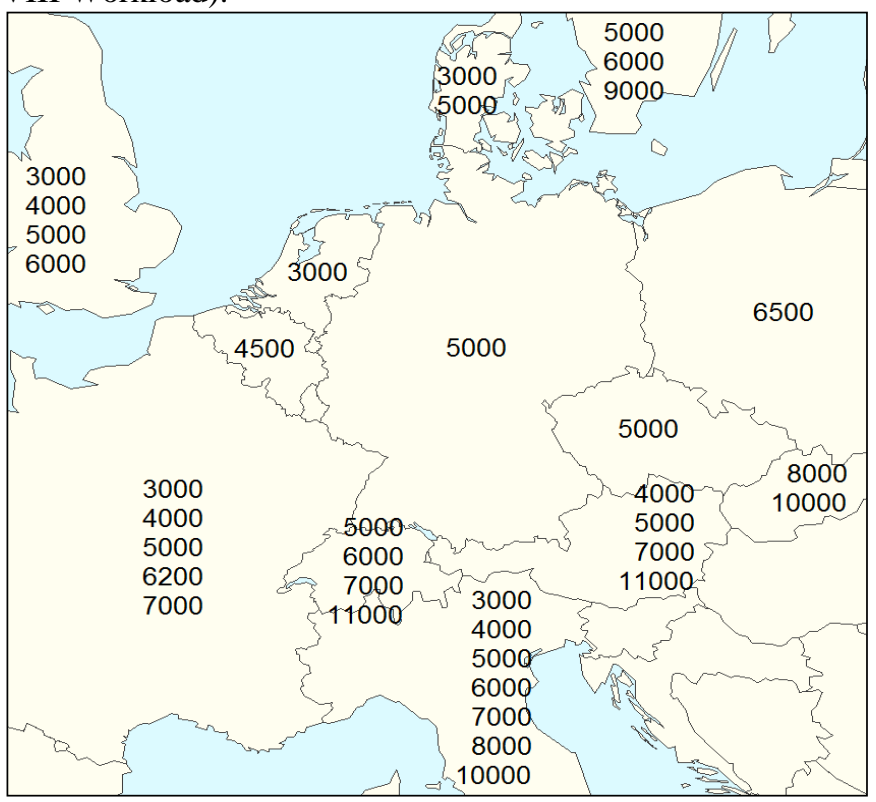

Figure 1 Use of different TAs in Central Europe as published in state AIPs,

(source: author)

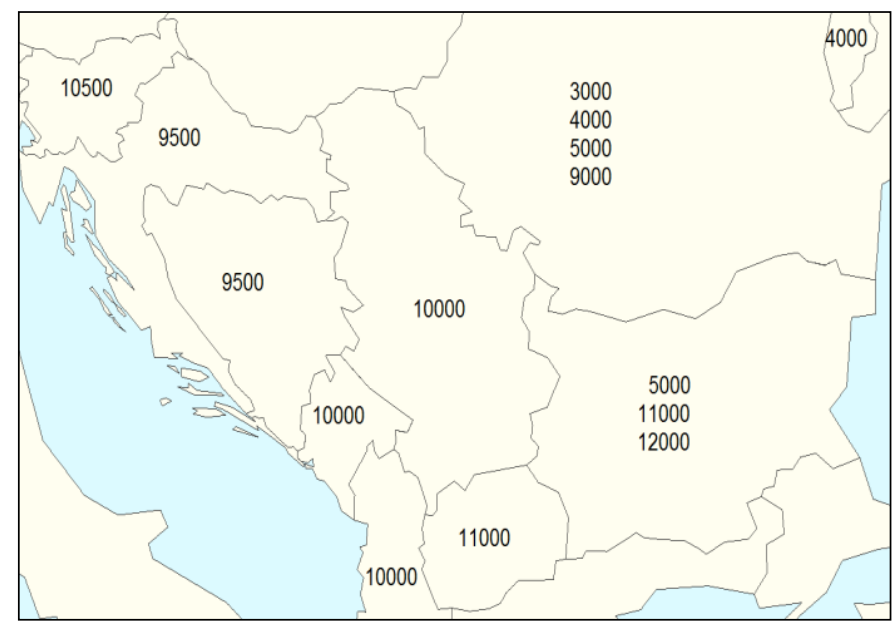

Figure 2 Use of different TAs in Balkans countries as published in state AIPs (source: author)
Note: countries in Figure 1 and 2 are titled by name of the main Air Navigation Services Provider (ANSP)

\section{Improper determination of TA values}

There are even regions in Europe where could be found the inappropriately determined TA values with respect to minimum obstacles altitudes/heights.

\section{Political and Social factors}

Significant factor contributing to the call for change of current settings is that the ICAO measures describing the determination of TA were adopted in late fifties and has not reflect both the current and latest flight procedures and harmonized rules for appointment of TAs. Historical lack of coordination among neighboring ANSPs and States when determining the TA strengthens the idea of harmonized TA.

\section{E. Safety factor}

Due to the variety of transition altitudes, increased vigilance from the flight crew is necessary to ensure that the correct altimeter setting is used. Altimeter mis-settings or omissions might occur when the transition needs to be performed during a period of high flight deck workload. Multiple transition altitudes do pose a safety risk. An obvious solution to reduce the safety risk is the introduction of a common transition altitude over an area as wide as possible.

\section{PROPOSED OPTIONS OF HARMONIZATION}

Current wording of ICAO PANS-OPS strongly recommends implementing the harmonized transition altitude within EUR region at altitude agreed by all concerns subjects (all countries within the region) but this altitude is not established yet. PANS-OPS. There is only simply noted, it should be:

(a) as low as possible over the airfield, but usually

(b) not below $3000 \mathrm{ft}$ AMSL (900 m).

It is also mentioned that calculated transition altitude has to be rounded to the next higher $1000 \mathrm{ft}(300 \mathrm{~m})$.

HETA-TF in its output (reflecting above mentioned facts) offers three alternative options of solution:
A. DO NOTHING
B. IMPLEMENT HETA AT 18000 FT AMSL
C. OMPLEMENT HETA AT 10000FT OR ABOVE

\section{A. Option $1-D O$ NOTHING}

There is no regulatory intervention expected in this option. That means the member states would continue to proceed with, current initiatives without a regulatory requirement. Option is often called as "Status Quo scenario".

\section{B. Option 2 - HARMONIZATION AT 18000 FT AMSL}

This option (HETA at $18000 \mathrm{ft}$ ) is supposed to take regulatory action. The TA value fixed at $18000 \mathrm{ft}$ is in line with current settings of TA in the USA and Canada (benefit for transatlantic flights). 


\section{Option 3 - HARMONIZATION AT 10000 FT OR ABOVE}

Last proposed option (marked 3) means implementing rule prescribing common criteria for the determination of the TA at or above $10000 \mathrm{ft}$ AMSL. Again, it would be regulatory action (as well as option 2) to implement a TA in Europe at or above $10000 \mathrm{ft}$, and this regulation should prescribe a the way how to reach the result in neighboring States/FABs/ANSPs when establishing harmonized TA and related procedures.

Detailed information about potential policy options could be found in [1], section 4.

\section{IDENTIFIED IMPACTS OF PROPSED SOLUTION}

In [6] are in details described identified impacts by established working group. Among monitored areas belong primarily impacts on:

(a) cabin crew (pilots) - change of currently used procedures

(b) air traffic controllers (ATCOs) - need of additional training to set up new procedures

(c) environment - esp. impact on Continuous Descent operation (CDO) and Continous Clib Operation (CCO)

(d) safety - level of change to existing safety levels

(e) economic - any extra cost related to implementation harmonized TA in respect of fuel consumption, additional training for staff, creation of new procedures.

Impacts for all above mentioned fields were evaluated for all three proposed solution of TA implementation ("do nothing", $18000 \mathrm{ft}, 10000 \mathrm{ft}$ ).

The low altitude band (equivalent to ,do nothing") is not suitable as a common transition altitude because it is located where the workload during climb and descent is the highest. It also interferes with several procedures that require a number of flight deck actions to be performed and therefore resetting the altimeter might easily be forgotten.

The medium altitude band (equivalent of implementation TA at $10000 \mathrm{ft}$ ) has clear advantages. The most of initial approach fixes (IAFs) defined for instrument approaches in the European airspace are set below this altitude band and there is no interference with most IFR flight operations procedures. There are only few airports within European area which need special procedures (or exceptions) and coordination conditions based on Letter of Agreement between ANSPs regarding TA.

The high altitude band (18000 ft) also has advantages, certainly in respect of flight deck workload (see figure 16), but to a lesser extent than the medium altitude band. The major disadvantages are:

- the setting of the altimeter comes too late after takeoff and could easily be forgotten;

- $\quad$ during descent the altimeter setting information might be outdated.

\section{CURRENT IMPLEMENTATION IN CENTRAL EUROPE}

As no mandatory EC Regulation to implement harmonized TA has appeared, some countries (ANSPs) have decided to create own concept of operations for harmonized TA based on recommendations of HETA Rule Making Group (HETA RMG). Recommendation - addressing states via EASA - are as follows:

- $\quad$ review the current value of the TA within their FIRs to ensure an optimum value for all airspace users, airspace design and modern flight procedures;

- when intending to change TA in the future, to coordinate with neighboring States to exploit the possibility of wider harmonization (e.g. as it was done for Austria, Slovakia and Hungary);

- whenever major changes to airspace design are planned, to consider raising the TA to a value at or above 10.000 feet (which could be possible case of the Czech Republic where is lower airspace redesign planned).

Central European countries (namely Austria, Hungary and Slovakia) have decided to harmonize their TA in the frame of common project called "TA10K". Providers in named countries believe that the idea of TA10K will increase safety, simplify ATCO's and pilot's work (in line with the arguments mentioned in sections II and IV) within the region and has a good prerequisite to be spread beyond the boundaries of implementing states.

First cross border coordination meeting between Slovakia (LPS) and Austria (Austrocontrol) was held in Bratislava on $4^{\text {th }}$ September 2014. Kick-off meeting of TA10K project was few months later $\left(20^{\text {th }}\right.$ January 2015 , Vienna) where was decided to implement TA $10000 \mathrm{ft}$ at Bratislava FIR and Vienna FIR with effect from $31^{\text {st }}$ March 2016. On meeting in Bratislava (14 ${ }^{\text {th }}$ April 2014) has decided Hungary (Hungarocontrol) to join this idea. It was decided about implementation of TA $10000 \mathrm{ft}$ in Budapest FIR with effect from $31^{\text {st }}$ March 2016 too (see figure 3 where are depicted FAB CE members countries with values of their TA from $31^{\text {st }}$ March 2016).

In figure 4, there is depicted current situation of TA 10000 $\mathrm{ft}$ implementation in Europe (WEF $31^{\text {st }}$ March 2016 - green color). Countries with orange background (Switzerland, the Czech Republic and Italy) are currently considering pros and cons of implementation TA10K. 


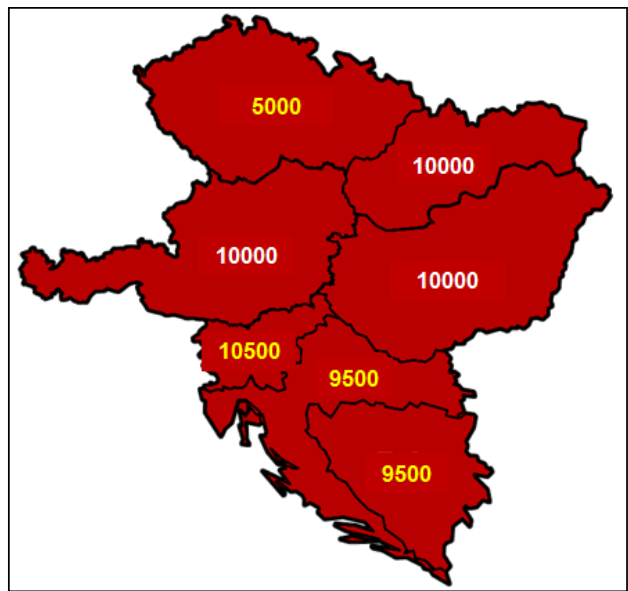

Figure 3 FAB CE member countries and their TAs, WEF $31^{\text {st }}$ March 2016, (source: [6])

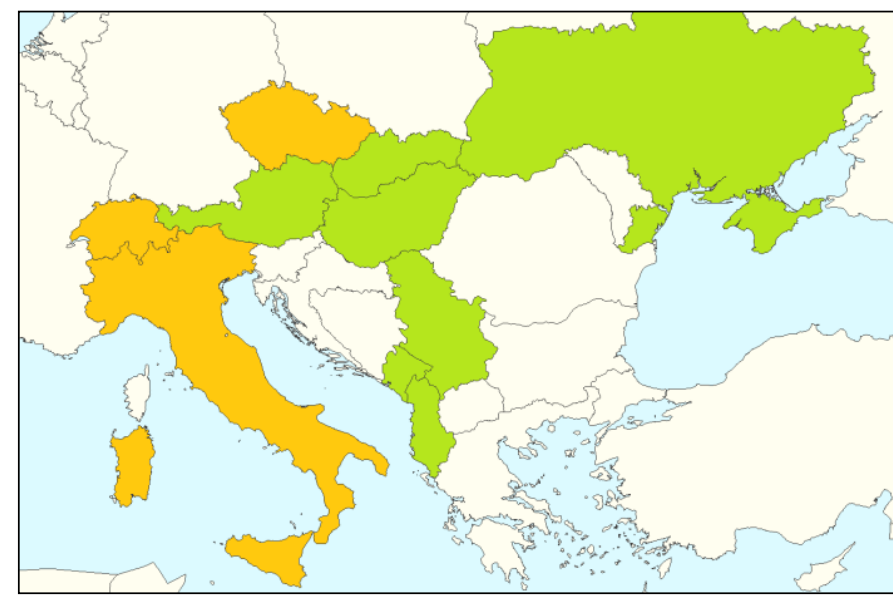

Figure 4 Implementation of TA10K WEF $31^{\text {st }}$ March 2016, (source: author)

\section{CURRENT IMPLEMENTATION OF TA10K IN SLOVAKIA}

Outside of civil and military TMAs horizontal boundary is applied regional QNH. This value is the minimum of forecasted QNH values in whole FIR region issued for the period of next three hours. (Note: the same principle is applied in the Czech Republic as well). See figure 5 for areas where aerodrome QNG (in TMAs) and where regional QNH (outside) are applied.

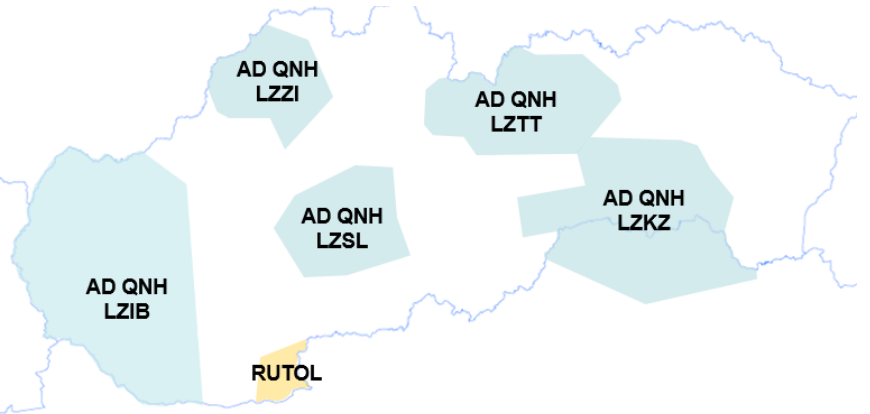

Figure 5 TMAs in Slovakia and AD QNH application, (source: [6])

It was proofed by analysis that there are certain periods when the values of regional QNH are not lower than measured aerodrome QNH. To mitigate this phenomena, the new methodology of regional QNH calculation has been proposed depending on comparison (aerodrome QNH minus regional $\mathrm{QNH})$ values of QNH.

\section{TABLE II. COMPARISON OF AERODROME AND REGIONAL QNH}

\begin{tabular}{|c|c|c|c|c|c|c|}
\hline \multicolumn{7}{|c|}{ AERODROME } \\
\hline comparison & LZIB & LZKZ & LZPP & LZSL & LZTT & LZZI \\
\hline$\geq \mathbf{0 ~ h P a}$ & 98,68 & 99,50 & 99,59 & 99,12 & 98,27 & 99,12 \\
\hline$<\mathbf{3 ~ h P a}$ & 34,24 & 31,70 & 33,18 & 27,10 & 20,61 & 29,97 \\
\hline$<\mathbf{0} \mathbf{~ h P a}$ & 1,34 & 0,50 & 0,41 & 0,88 & 1,73 & 0,88 \\
\hline
\end{tabular}

Note: all values are in \%; values are frequency of occurrence when difference is as stated in the first column

To mitigate unwanted phenomena, the methodology of regional QNH calculation was proposed to ensure (to the greatest extent possible) that:

aerodrome $Q N H_{\text {min }}$ - regional $Q N H \geq 0 \mathrm{hPa}$

aerodrome $\mathrm{QNH}_{\min }-$ regional $\mathrm{QNH}<4 \mathrm{hPa}$

Formula for QNH calculation consists of the following items:

- given flight level (FL),

- $\quad$ altitude in feet (ALT) and

- minimum required vertical separation between FL and ALT in feet (MVS),

then the minimum QNH value to comply with MVS will be:

$$
Q N H=1013.25 \times\left[1-6.87559 \times 10^{-6} \times(F L \times 100-A L T-\right.
$$

- this formula is derived from Doc 7488, Manual of the ICAO standard atmosphere, equation 12; results match Doc 9426, ATS Pl. Manual, Part II, Section 5, Chapter I,

- $\quad$ versatile usage of TL, arbitrary values of FL, ALT and MVS allowed,

- $\quad$ round up to obtain lower bound of QNH interval for given FL,

- $\quad$ round down to obtain upper bound of QNH interval for next higher to given FL.

Given FL = TL (transition level), ALT $=10000 \mathrm{ft}, \mathrm{MVS}$ $=1,000 \mathrm{ft} \mathrm{QNH}$ interval results as follows in table III.

TABLE III. DETERMINATION OF TRANSITION LEVELS ACCORDINAG TO QNH VALUES IN LZBB AND LKAA

\begin{tabular}{|c|c|c|c|}
\hline \multicolumn{2}{|c|}{ QNH intervals $[\mathrm{hPa}]$} & TL (LZBB) & TL (LKAA) \\
\hline 943 & 977 & 130 & $\mathbf{8 0}$ \\
\hline 978 & 1013 & 120 & 70 \\
\hline 1014 & 1050 & 110 & 60 \\
\hline 1051 & 1058 & 100 & 50 \\
\hline
\end{tabular}

In table IV could be found the values of probability of occurrences of transition levels based on QNH history at the airport LZBB, LZIB, LZKZ, LZPP, LZSL, LZTT, LZZI. 
TABLE IV. COMPARISON OF AERODROME AND REGIONAL QNH

\begin{tabular}{|c|c|c|c|c|c|c|c|}
\hline \multicolumn{7}{|c|}{ Probability of occurrence of TL based on QNH history } \\
\hline TL & LZBB & LZIB & LZKZ & LZPP & LZSL & LZTT & LZZI \\
\hline $\mathbf{1 3 0}$ & $0.04 \%$ & $0.08 \%$ & $0.11 \%$ & $0.10 \%$ & $0.12 \%$ & $0.14 \%$ & $0.12 \%$ \\
\hline $\mathbf{1 2 0}$ & $49.8 \%$ & $32.7 \%$ & $33.9 \%$ & $32.8 \%$ & $34.3 \%$ & $35.5 \%$ & $32.4 \%$ \\
\hline $\mathbf{1 1 0}$ & $50.2 \%$ & $67.3 \%$ & $66.0 \%$ & $67.2 \%$ & $65.6 \%$ & $64.4 \%$ & $67.5 \%$ \\
\hline $\mathbf{1 0 0}$ & $0.00 \%$ & $0.00 \%$ & $0.00 \%$ & $0.00 \%$ & $0.00 \%$ & $0.00 \%$ & $0.00 \%$ \\
\hline
\end{tabular}

For simplification were only two intervals of regional QNHs considered:

- $\quad 978-1013 \mathrm{hPa}$

- $\quad 1014-1051 \mathrm{hPa}$

which take $99,9 \%$ of cases also taking into account following assumptions:

- $\quad$ there is only one transition altitude (TA) within whole FIR (based on aerodrome and regional QNH) and

- only one transition level (TL) within whole FIR (based on regional QNH) and finally

- $\quad$ minimum $1000 \mathrm{ft}$ is between TA and TL (ICAO Doc. 7030)

There were created and tested three scenarios to assure that all assumptions mentioned above will be respected:

(A) aerodrome $\mathrm{QNH} \geq 1014$, regional $\mathrm{QNH} \geq 1014$

(B) aerodrome $\mathrm{QNH} \leq 1013$, regional $\mathrm{QNH} \leq 1013$

(C) aerodrome $\mathrm{QNH} \geq 1014$, regional $\mathrm{QNH} \leq 1013$.

The probabilities of these scenarios are:

- $\quad 47,6 \%$ for scenario (A) - see figure 6 ,

- $\quad 33,4 \%$ for scenario (B) - see figure 7 ,

- $\quad 18,0 \%$ for scenario $(\mathrm{C})$ - see figure 8 .

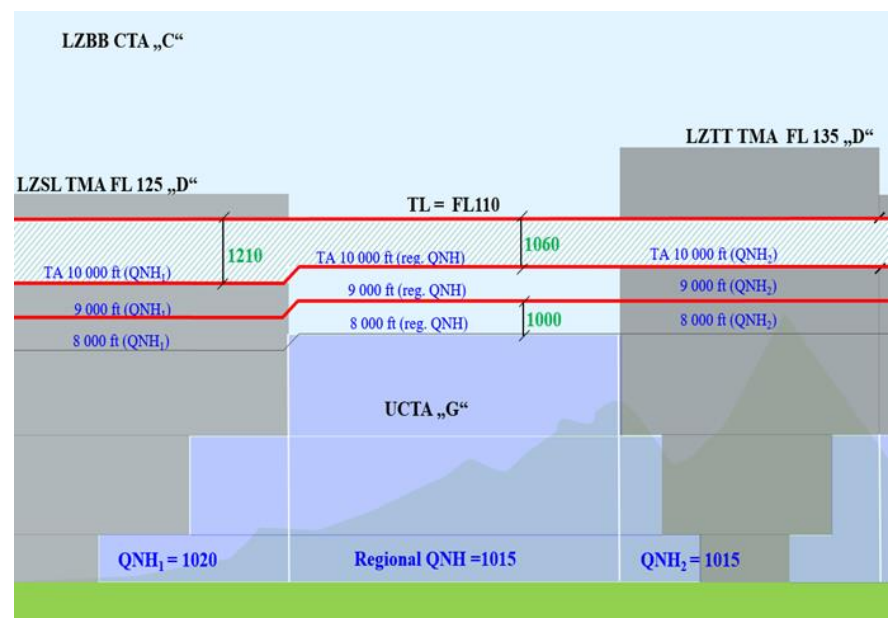

Figure 6 Scenario (A) aerodrome $\mathrm{QNH} \geq 1014$, regional $\mathrm{QNH} \geq 1014$, source: [6])

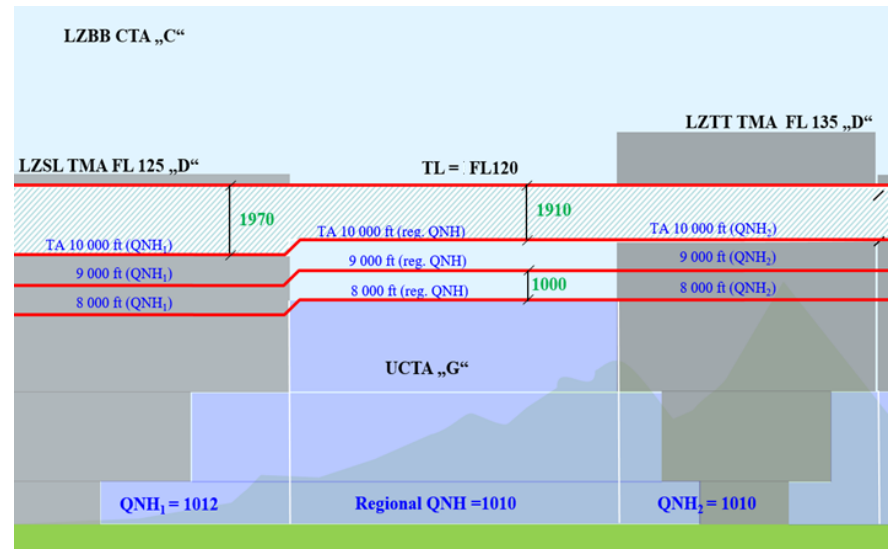

Figure 7 Scenario (B) aerodrome QNH $\leq 1013$, regional QNH $\leq 1013$ (source: [6])

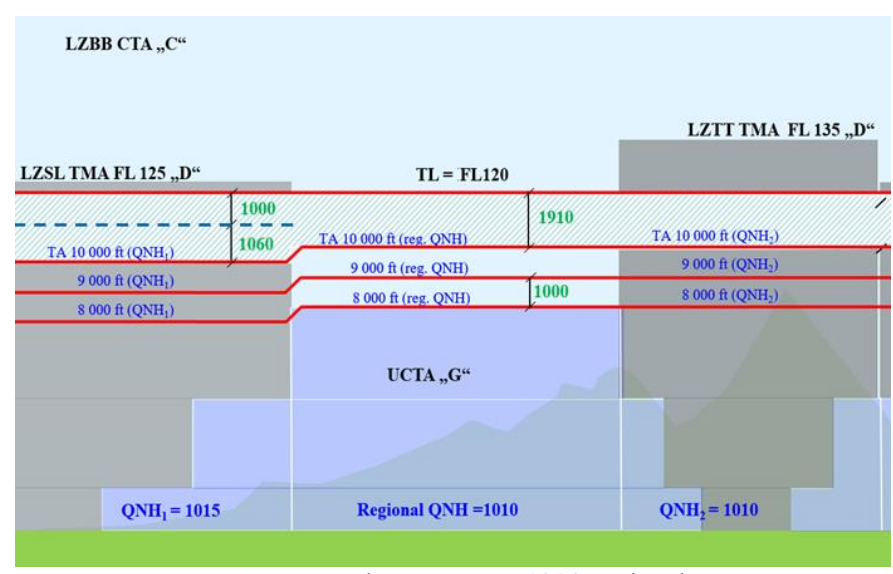

Figure 8 Scenario $(C)$ aerodrome $\mathrm{QNH} \geq 1014$, regional $\mathrm{QNH} \leq 1013$, (source: [6])

\section{APPLICATION OF DIFFERENT ALTIMETER SETTING RULES IN THE ACI AT THE INTERFACE BETWEEN LKAA / LZBB / LOVV IN SLOVAKIA}

In this section are all examples and pressure to level conversions based on simplified coefficient where $1 \mathrm{hPa}=30 \mathrm{ft}$ (according the ICAO Doc 8168 OPS Vol. II - Aircraft Operations). There are not considered any temperature effects on altimetry.

Basic assumptions are that aircraft shall maintain the rules for altimeter settings valid for given FIR where flying. The altimeter setting change occurs at FIR boundary in accordance with the upstream FIR rules (or according to the controller's instruction as described in next sentence). The only exception from this rule is represented by the situations when a verbal coordination precedes full release for vertical changes prior crossing the FIR boundary. A special stress has to be put on this fact within the airspaces where the ATS provision has been delegated between the states with different rules. In addition to such an airspace where moreover the Class $\mathrm{E}$ is on place the domestic uncontrolled traffic uses the rules for appropriate FIR regardless such a delegation between ATS providers.

As soon as the flight adjusts altimeter settings on the event of crossing FIR boundary it has to arrange its vertical position accordingly by climb or descent whenever the atmospheric 
pressure situation differs from standard pressure value of $1013,25 \mathrm{hPa}$ in both FIRs (what is the most prevailing case).

Vertical difference between aircraft flying in the same FIR on different QNH setting because of different area of responsibility (etc. on regional QNH and on aerodrome QNH in TMAs) will be calculated by adding or subtracting hereunder mentioned values. It must be noted that these calculations are very simplified and its purpose is only to understand the changes between levels depending on the altimeter settings. See figure 9 where are displayed relative frequencies of aerodrome and regional QNH and derived transition level based on QNH value on LKAA.

Figures 10 - 13 show various combinations which can obviously occur. It is really not easy to calculate the exact vertical separation for air traffic controllers in the area imminently in vicinity of the interface, especially during the low atmospheric pressure situations. In fact, the different altimeter settings rules create in that area a kind of "extended transition layer" beginning at transition altitude of $5000 \mathrm{ft}$ in the Czech Republic extended up to transition levels in FIR Vienna and the FIR Bratislava. Therefore, whenever a mixed condition occurs (and especially in low atmospheric situations), it is highly recommended to prioritize a lateral separation between conflicting flightss. When separating vertically, the same principle should be applied as for the transition layer today, which has to be at least $1000 \mathrm{ft}$ thick.
Note: upper limit of TMA LZZI will be all the time at altitude $9500 \mathrm{ft}$ AMSL.

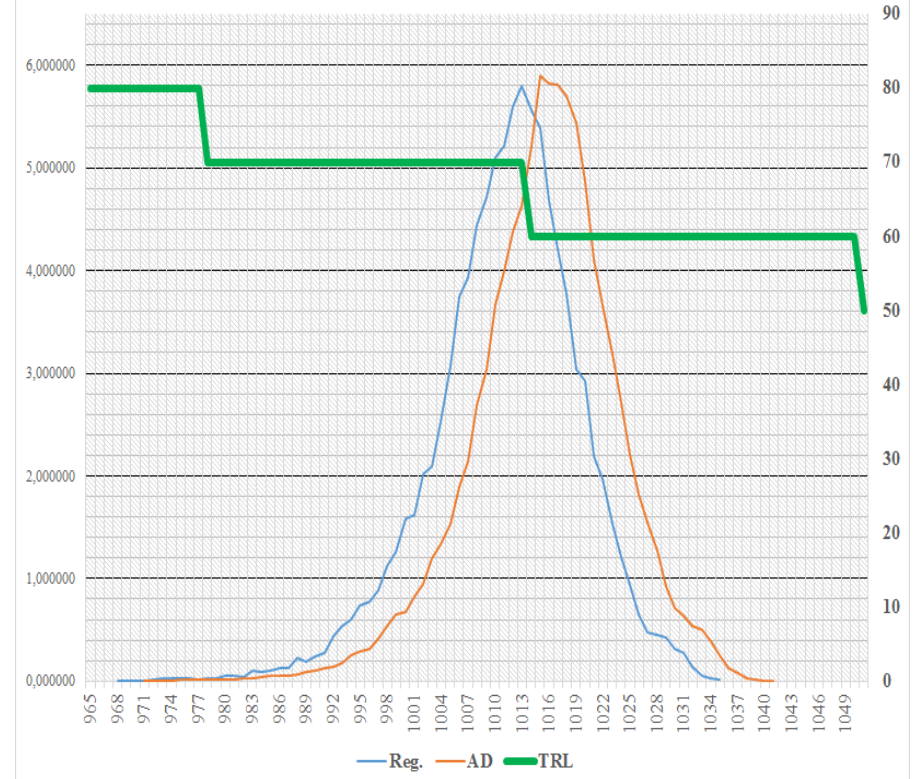

Figure 9 Relative frequencies of aerodrome (red) and regional (blue) QNH and derived transition level (green) in LKAA (FIR Prague), (source: author) Note: axis $x-Q N H$ value ( $h P a)$, axis y (left) - relative frequency, axis y (right) - transition level $(\mathrm{hPa})$

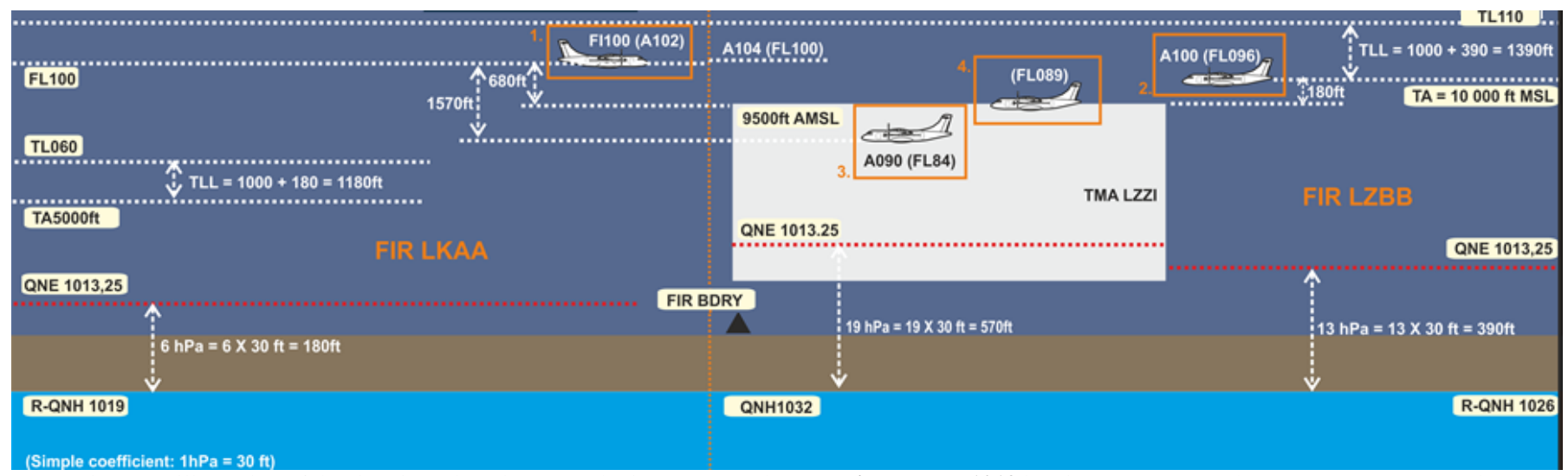

Figure 10 illustration of the situation when the atmospheric pressure values are higher than $1013 \mathrm{hPa}$ in FIR LKAA and FIR LZBB, (source: author)

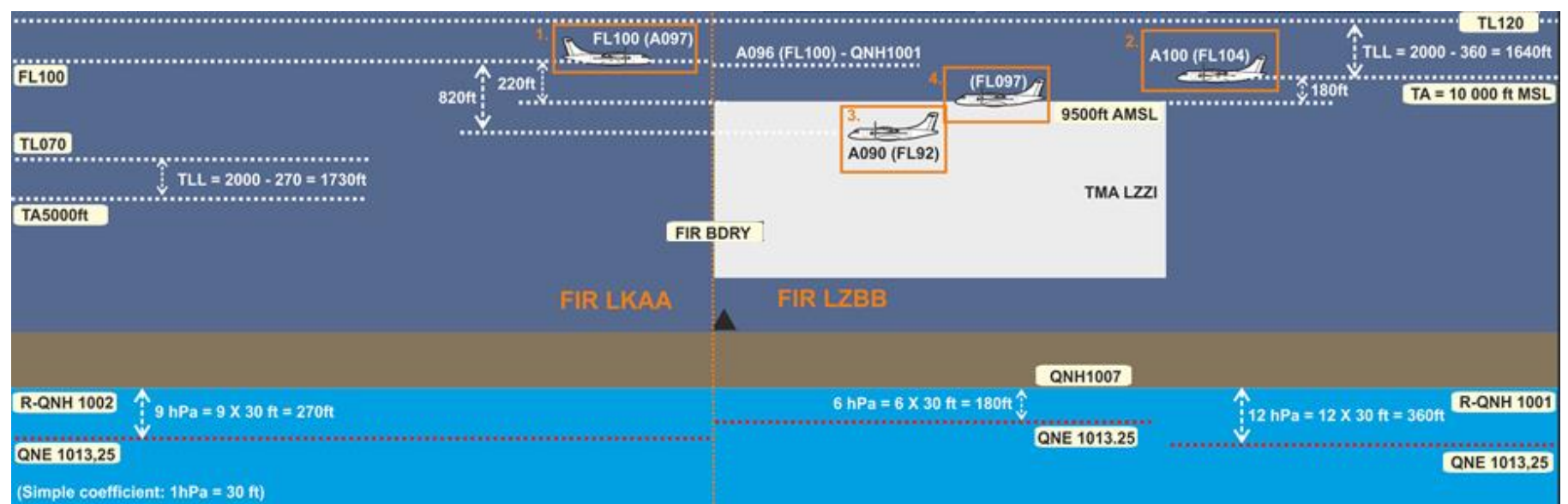

Figure 11 illustration of the situation when the atmospheric pressure values are lower than 1013 hPa in FIR LKAA and FIR LZBB, (source: author) 


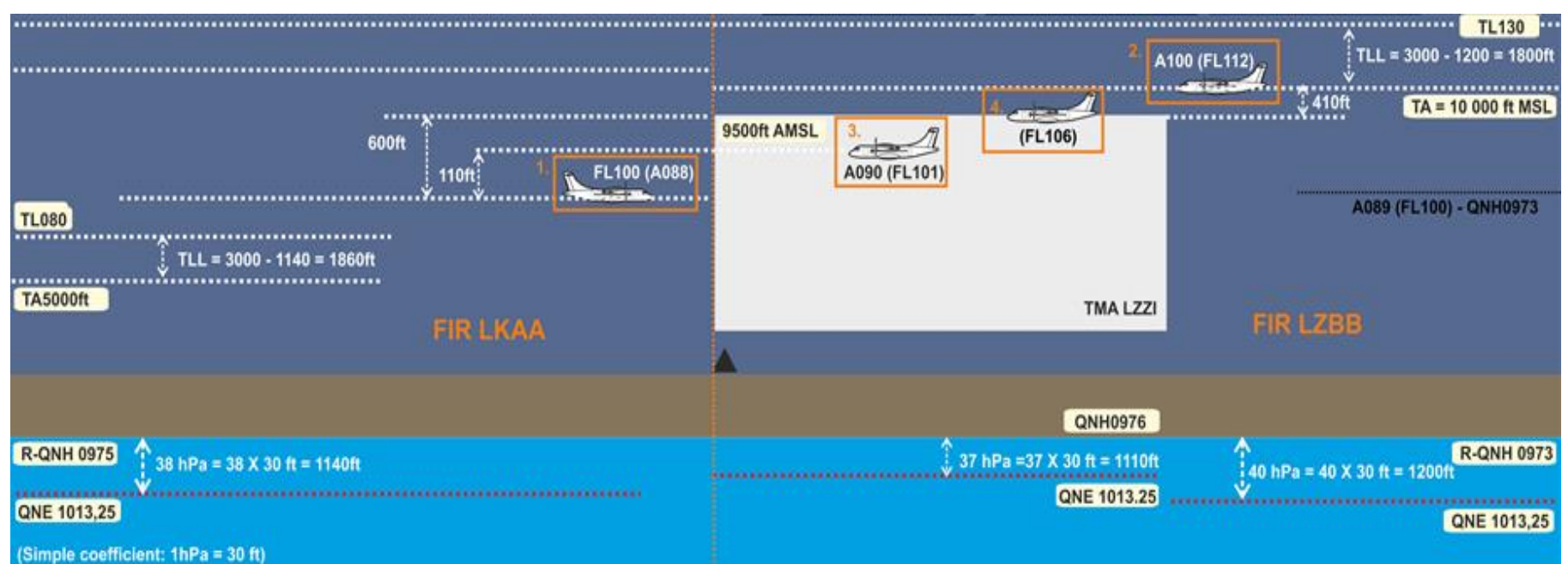

Figure 12 illustration of the situation when the atmospheric pressure values are lower than $0977 \mathrm{hPa}$ in FIR LKAA and FIR LZBB, (source: author)

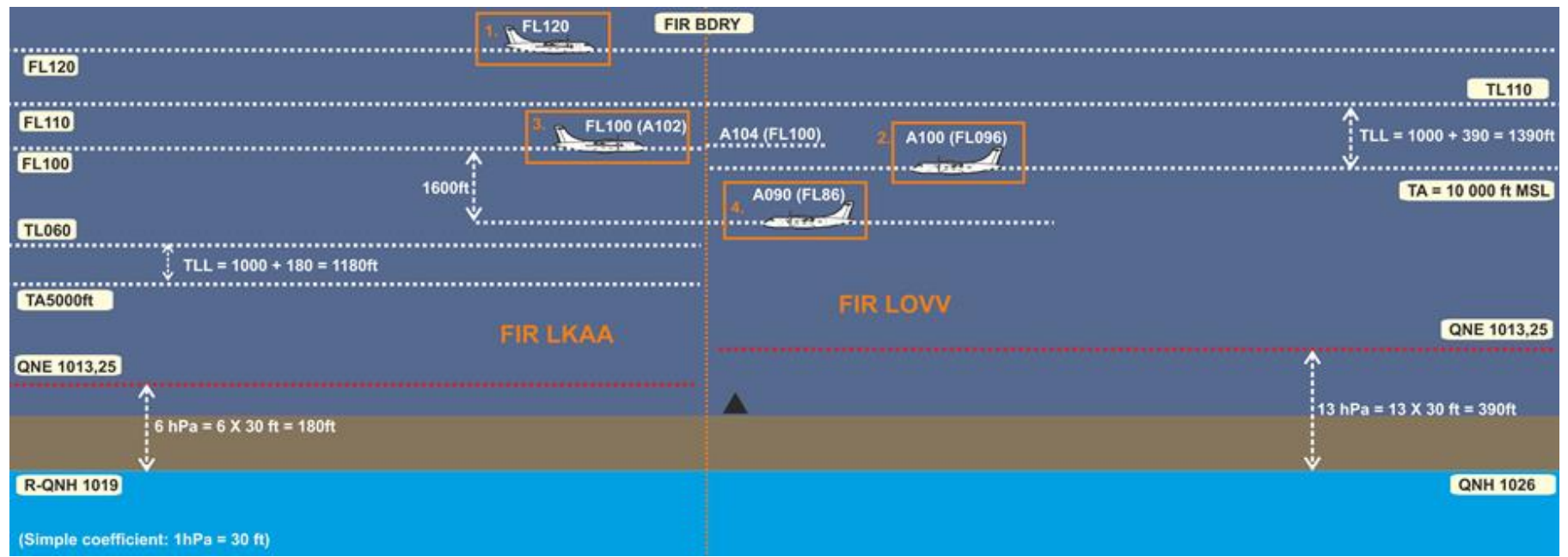

Figure 13 illustration of the situation when the atmospheric pressure values are higher than $1013 \mathrm{hPa}$ in FIR LKAA and FIR LOVV, (source: author)

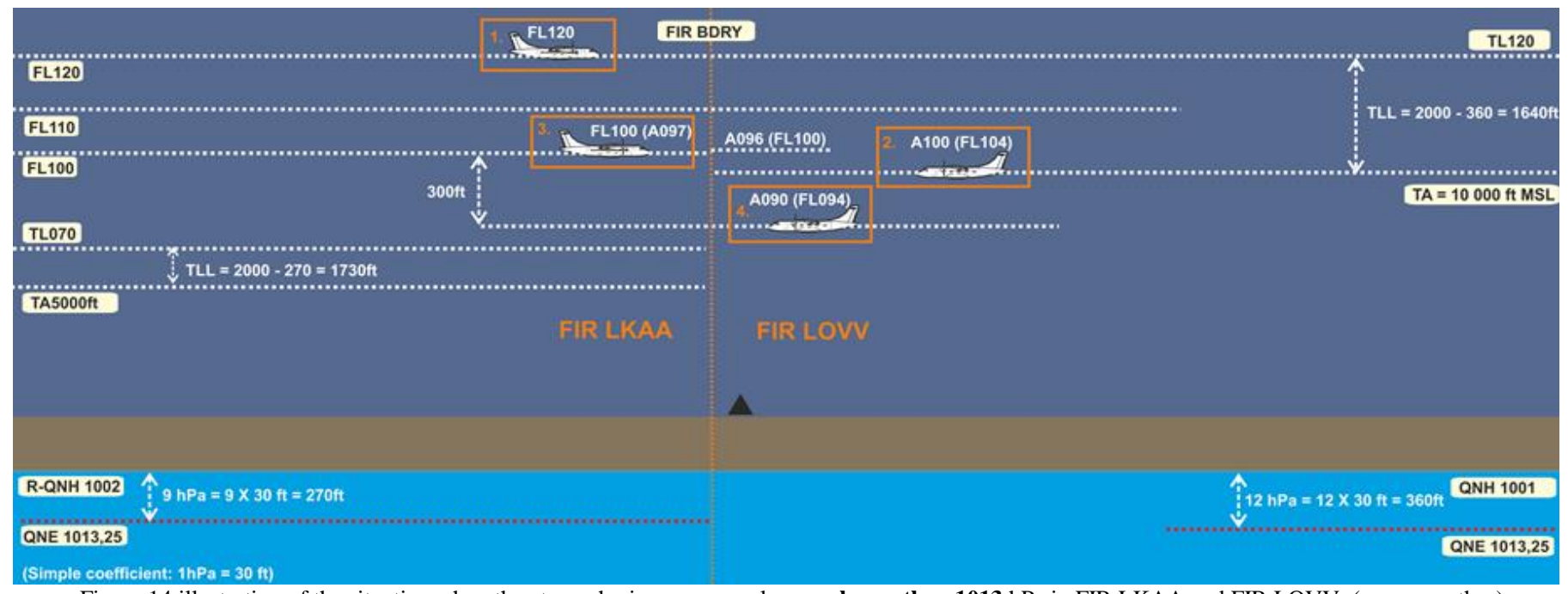

Figure 14 illustration of the situation when the atmospheric pressure values are lower than $1013 \mathrm{hPa}$ in FIR LKAA and FIR LOVV, (source: author) 


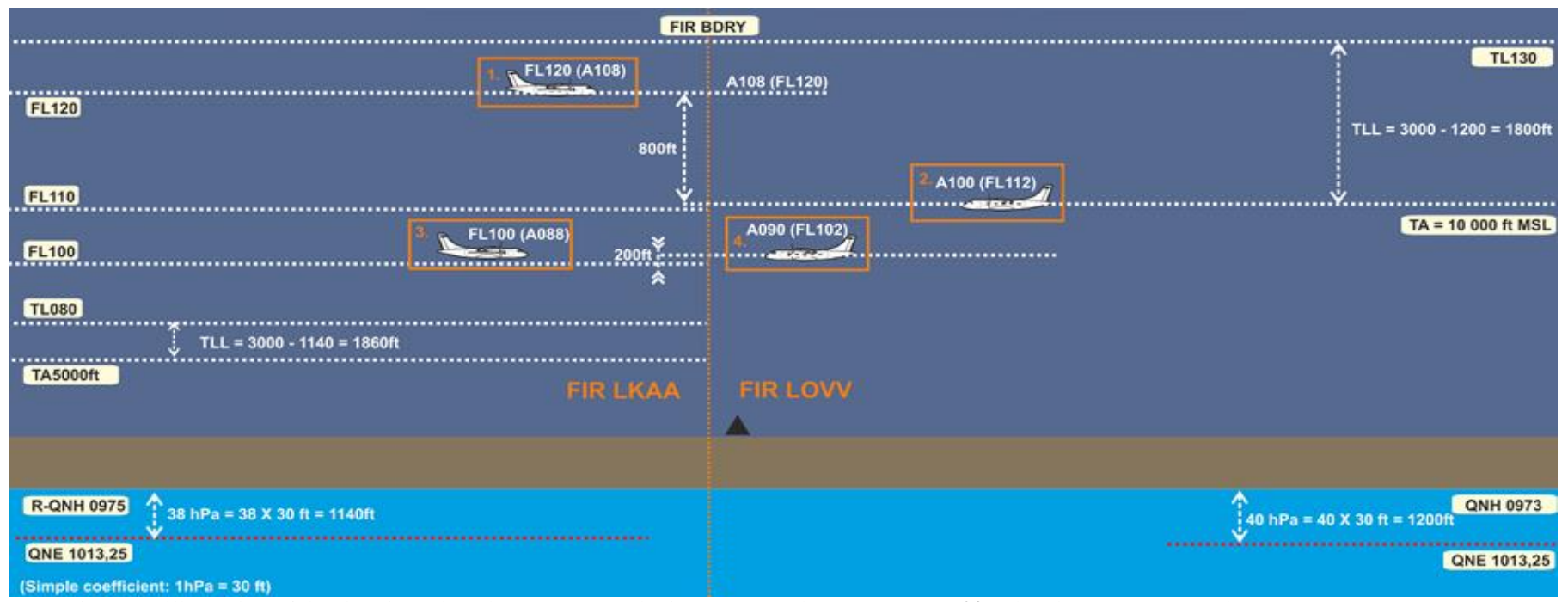

Figure 15 illustration of the situation when there are atmospheric pressure values lower than 0977 hPa in FIR LKAA and FIR LOVV, (source: author)

\section{WORKLOAD}

In section II, paragraph E Safety factors is mentioned, that huge variety of TAs can be considered as safety risk and in paragraph $\mathrm{B}$ explains the necessity to reset altimeter during crucial phase of the flight. Transition altitude and altimeter setting are strongly related. A transition altitude where the workload is high (approach phase) can be the cause of an increase in errors. In [2] was made a survey that shows following facts. The workload during cruise is much lower and less critical than during landing and take-off. It is interesting to know where the turning point between low and high workload can be situated. Obviously, the transition altitude should not fall in the middle of a high workload phase or a critical phase of flight. In figure 16 is displayed workload on flight deck during climbing (blue) after departure and descending (red) to destination. Note that survey was done for airport located mainly at sea level where the TA value is typically also very low (e.g. $3-5000 \mathrm{ft}$ ), which are the busiest altitude in terms of actions taken by the crew.

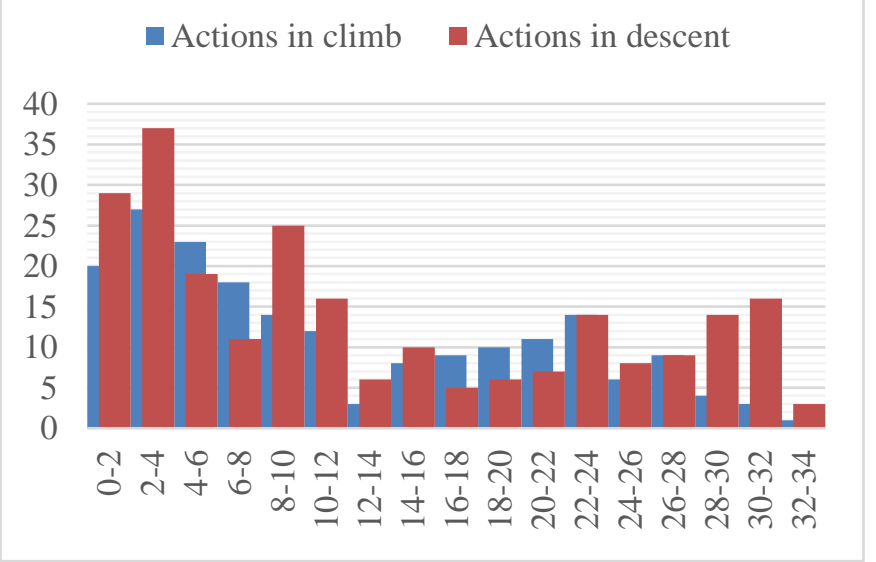

Figure 16 Number of actions on flight deck during climb and descent Note: axis $\mathrm{x}=$ altitudes in $1000 \mathrm{ft}]$, axis $\mathrm{y}=$ number of actions taken on deck (data source: [2], graph redesigned by author)

\section{CONCLUSION}

There are no doubts that harmonized transition altitude across Europe is really big benefit for many concerned subjects. Although there was not created by working groups, which was established for this purpose, the common EC Regulation ordering the implementation harmonized transition altitude in all European countries, there is obviously growing effort for cross border cooperation in terms of implementation the harmonized TA. On the other hand must be said that only partial implementation of harmonized TA only in some parts of the region devalues the real advantages of fully harmonized solution in all its aspects including safety. For unspecified period, there will be still scrappy parts of airspace with different values of TA and different rules. Furthermore, as shown in section VI, the process of implementation is not as easy as it looks for the first view. It is clear that until the fully implemented harmonized TA within the whole European region, there will be significant hotspots on boundaries where areas with different TA values meets as it is described in section VII (examples of operational situations on boundary between LKAA and LOVV/LZBB). That can be considered as a certain safety risk and air traffic controllers have to put special effort to aircraft and its altimeter settings flying through such areas at affected flight levels between TAs in adjacent ATS units.

It has to be acknowledged that the process of TA10K implementation has already started in European region. Hopefully, also other countries (resp. their air navigation services providers - as showed in figure 4) will set out on way of idea to implement TA10K because this is the only way how to soften current inhomogeneous ambience of TAs within Europe. 


\section{ACRONYMS}

FIR - Flight Information Region

TA - Transition Altitude

TL - Transition Level

FL - Flight Level

LKAA - FIR Prague

LOVV - FIR Vienna

LZBB - FIR Bratislava

EC - European Commission

HETA - Harmonizes European Transition Altitude

QNH - Atmospheric Pressure (Q) at Nautical Height (NH)

AD QNH - see QNH

R-QNH - Regional QNH

ATCO - Air Traffic Controller

ANSP - Air Navigation Service Provider

FAB - Functional Airspace Block

EASA - European Aviation Safety Agency

TMA - Terminal Area

CTA - Control Area

UCTA - Uncontrolled Area

TA10K - Transition Altitude 10 Kilo

FAB CE - Functional Airspace Block Central Europe

MVS - Minimum Vertical Separation

\section{REFERENCES}

[1] EASA, Advance Notice of Proposed Amendment A-NPA 2012-01 Harmonised Transition Altitude, published 20.3. 2012

[2] EUROCONTROL, Towards a Common Transition Altitude - A Flight Deck Perpective. Available from:

https://www.eurocontrol.int/sites/default/files/field tabs/content/docume nts/nm/airspace/airspace-atmprocedures-flight-deck-perspective.pdf

[3] ICAO, Doc. 4444, Air Traffic Management [online]. Montreal, 2007. Available from:

http://dcaa.trafikstyrelsen.dk:8000/icaodocs/Doc\%204444\%20\%20Air\%20Traffic\%20Management/ATM\%20\%2015\%20ed.pdf

[4] ICAO Doc. 7030 Regional Supplementary Procedures [online] Montreal, 2008. Available from: http://dcaa.trafikstyrelsen.dk:8000/icaodocs/Doc\%207030/7030_cons_e n\%20-\%20Regional\%20Supplementary\%20Procedures.pdfP.

[5] Běleš, Změny pravidel a postupů, preserntation; ANS CZ, Development and planning division, procedures department, 8. 2. 2014

http://lis.rlp.cz/cz/prezentaceGA2014/ZmenyPravidelAPostupu.ppt

[6] R. Primus, TA10K progress meeting LPS-ACG-HCL - Common TA at $10000 \mathrm{ft}$ AMSL, presentation, LPS SR, Bratislava 5. 11: 2015

[7] CAA UK, Transition altitude (TA), information leeflet, April 2015, http://www.ukfsc.co.uk/files/Safety\%20Briefings\%20\%20Presentation s/2012/ATM\%20-

\%20CAA\%20TA\%20Update\%20\%20April $\% 202015$.pdf

[8] LPS SR, Ausotrocontrol, Hungarocontrol, CONOPS of TA10K, version 0.9

[9] EUROCONTROL, General Issues and Information, HETA working group results, 2013 